\title{
1 Comparison of defence buzzes in hoverflies and buzz-pollinating bees
}

2

Mario Vallejo-Marín ${ }^{1, *}$

$4 \quad$ Gillian C. Vallejo ${ }^{2}$

5

$6{ }^{1}$ Department of Biological and Environmental Sciences. University of Stirling. Stirling, FK9 4LA, 7 Scotland, United Kingdom.

$8{ }^{2}$ Natural Power Consultants. Ochil House, Springkerse Business Park, Stirling FK7 7XE, Scotland, $9 \quad$ United Kingdom.

10

$11 *$ Author for correspondence: mario.vallejo@stir.ac.uk

13 Running title: Defence buzzes in hoverflies and bees 


\section{Abstract}

Bees and many flies, particularly hoverflies (Syrphidae), have evolved a diverse range of mechanisms to gather pollen from a wide variety of flowering plants. Bees and hoverflies use protein-rich pollen as a food resource to mature reproductive organs and eggs and, in bees, to feed their larvae. A particularly striking pollen-collecting behaviour involves the production of thoracic vibrations to dislodge pollen from flowers. Vibratile pollen collection is widespread in bees ( $>11,600$ species) but extremely rare in flies ( 1 species of hoverfly). Why the use of floral vibrations to collect pollen is so rare among flies is currently unknown. A hypothesis proposed to explain why flies do not engage in vibratile or buzz pollination is that they are unable to reach the vibration amplitude required to expel pollen from anthers. Here we document, for the first time, the mechanical properties of nonflight thoracic vibrations produced by hoverflies and compare them to the vibrations produced by buzz-pollinating bees under similar contexts (defence buzzes). We analysed $\sim 4,000$ vibrations produced by nearly 300 individuals representing 20 species of hoverflies and 22 bee taxa, recorded using a miniature piezoelectric accelerometer. We characterised both frequency and acceleration amplitude components of non-flight thoracic vibrations and their relationship to insect size. Our results show that, after accounting for size, buzz-pollinating bees and hoverflies produce vibrations with similar acceleration. We show experimentally that the acceleration amplitude produced by some hoverflies is sufficient to elicit pollen release from buzz-pollinated flowers (Solanum dulcamara and S. rostratum). Our study does not support the hypothesis that the dearth of buzzpollinating flies is caused by their inability to produce vibrations of sufficient amplitude. We discuss alternative hypotheses to explain why most flies do not engage in buzz pollination and suggest that the lack of buzz-pollinating flies might be best explained through their life history.

Keywords: Bees, behaviour, biomechanics, buzz pollination, flies, Syrphidae. 
Introduction

In addition to collecting nectar and other floral resources, bees (Hymenoptera: Apoidea: Anthophila) and some flies (Diptera) visit a wide diversity of flowering plants to gather pollen (Thorp 2000, Woodcock et al. 2014, Cook et al. 2020). Pollen consumption is known in fly species in the families Bombyliidae, Empididae, Muscidae, Tabanidae, Ceratopogonidae, and particularly Syrphidae (Inouye et al. 2015). Pollen is an essential resource for bees and hoverflies (Syrphidae), because the nutritious, protein-rich pollen grains are used to support development of sexual organs and to build nitrogen reserves in the eggs (Kevan \& Baker 1983, Thorp 2000, Larson et al. 2001). In flies, pollen consumption mostly occurs in the adult stage, although in some flower-brooding hoverflies, larvae can also feed on pollen (Holloway 1976, Nunes-Silva et al. 2010, Inouye et al. 2015). However in bees, pollen is needed to feed larvae in both solitary and social species (Thorp 2000). Thus, more than 6,000 species of hoverflies (McAlister 2017) and 20,000 species of bees (Danforth et al. 2019) depend heavily on pollen collection.

Bees and hoverflies have evolved a distinct set of structural and behavioural adaptations to extract pollen from flowers. In bees, specialised structures to collect pollen include hooked hairs on legs and mouthparts, or clusters of hairs on the top of the head (Thorp 1979, 2000). Moreover, the majority have external structures specialised for pollen transport (Thorp 2000), including modified hairs forming corbiculae in legs (e.g. Apidae) or scopae in legs or other body parts (Thorp 2000). Structural adaptations for pollen collection in flies are less well-studied. Examples include the presence of branched, plumose, or curly-tipped body hairs that help pollen to adhere to the body. More rarely, some hoverflies also use bristles arranged in combs in their legs to aid with pollen collection (Holloway 1976, Larson et al. 2001), and males of Platycheirus spp. use flattened tarsi to squeeze pollen out of anthers (Inouye et al. 2015). In contrast to bees, hoverflies do not need to transport large amounts of pollen as they consume it directly from the anther or from their bodies during floral visitation (Larson et al. 2001).

As well as structural differences, there are also behavioural differences associated with pollen collection between bees and flies. Pollen collection in bees involves scraping, rubbing, tapping and rasping with their legs or other body parts (Thorp 2000, Russell et al. 2017, Konzmann et al. 2019, Portman et al. 2019). Hoverflies use pollen grooming and scraping routines, either while hovering or resting, to collect and consume pollen accumulated in or actively transferred to their front legs (Holloway 1976). A particularly striking behavioural difference among pollen-collecting bees and hoverflies is their ability to produce vibrations to remove pollen from flowers, also known as floral vibrations or sonication (Rick 1950, Michener 1962, Buchmann et al. 1977, Vallejo-Marin 
2019). While the behaviour of producing floral vibrations has evolved more than 40 separate times in $58 \%$ of the 20,000 species of bees (Cardinal et al. 2018), very few of the 6,000 species of hoverflies are known to use vibrations to collect pollen from flowers (Figure 1). The only published exception is the Mexican cactus fly, Copestylum mexicanum (formerly Volucella mexicana), which vibrates Solanum douglasii (Buchmann et al. 1977). Why the use of floral vibrations to collect pollen is so rare among flies is currently unknown.

Floral vibrations are one of several types of non-flight thoracic vibrations produced by bees and flies across different behavioural contexts (Buchmann 1983, Hrncir et al. 2005, Rashed et al. 2009). Non-flight thoracic vibrations are produced by the same asynchronous muscles that power flight in both bees and flies (King et al. 1996, Dickinson et al. 1998, Pritchard \& Vallejo-Marín 2020b). Social bees in the genera Apis and Melipona use thoracic vibrations to communicate with nestmates (Hrncir et al. 2005, Hrncir et al. 2011), while males of the solitary bee Osmia bicornis use vibrations to entice females to mate (Conrad \& Ayasse 2015). Moreover, bees and hoverflies produce nonflight thoracic vibrations under duress as an alarm, warning or deterrence signal. In bees, these "defence buzzes" serve as an alarm or aposematic signal to deter potential predators (Kirchner \& Röschard 1999). Hoverflies also produce defence buzzes, and it has been suggested that they represent either a general alarm signal or acoustic mimicry with bees (Rashed et al. 2009, Moore \& Hassall 2016).

One hypothesis that could explain why flies do not use vibrations on flowers is that they are unable to reach the vibration amplitude required to expel pollen from anthers. Although bees apply vibrations to remove pollen from many different types of flowers, the use of floral vibrations is strongly associated with buzz-pollinated "poricidal flowers", flowers in which pollen is concealed in structures, usually made of enlarged anthers, that open only through small apertures or pores (Buchmann 1983, De Luca \& Vallejo-Marin 2013, Russell et al. 2017). Theoretical and experimental studies of buzz-pollinated flowers, show that the amplitude of the vibration (measured as acceleration, velocity or displacement) determines pollen release (Buchmann \& Hurley 1978, De Luca et al. 2013, Rosi-Denadai et al. 2020). King \& Buchmann (2003) proposed the hypothesis that an inability to reach the required acceleration amplitude could explain why some bees, such as Apis mellifera, do not employ vibrations to remove pollen from poricidal flowers. This hypothesis could be extended to other floral visitors including flies, generating the prediction that hoverflies should generally achieve lower acceleration amplitudes than buzz-pollinating bees.

Since most hoverflies do not produce floral vibrations, addressing this hypothesis requires the comparison of other types of non-flight thoracic vibrations. Defence vibrations provide such an 
opportunity as they occur across taxa and can be experimentally induced in both bees and hoverflies (Rashed et al. 2009, De Luca et al. 2014, Moore \& Hassall 2016, Pritchard \& Vallejo-Marín 2020b). However, when using defence vibrations to test hypotheses related to pollen release from flowers, it is important to consider that vibrations across different behaviours have different properties (Hrncir et al. 2005). The properties of defence vibrations compared to floral vibrations have only been studied in a handful of bee species. Use of non-contact laser vibrometry to measure vibrations directly on the thorax of $B$. terrestris ssp. audax shows that floral vibrations have higher frequencies than defence vibrations ( $313 \pm 3$ vs. $236 \pm 4 \mathrm{~Hz}$ ), and larger peak acceleration amplitude (518 \pm 19 vs $297 \pm 12 \mathrm{~ms}^{-2}$ ) (Pritchard \& Vallejo-Marín 2020b). Therefore, defence vibrations may provide a conservative estimate of the acceleration amplitude produced during floral vibrations.

Here, we compare defence vibrations produced by different species of buzz-pollinating bees and hoverflies and determine their capacity to release pollen from buzz-pollinated flowers. We address three main questions: (1) What is the relationship between insect size and peak acceleration of non-flight thoracic vibrations? Previous work has shown that within a single bumblebee species (Bombus terrestris), individual size is positively correlated with peak velocity (De Luca et al. 2013). We therefore hypothesise that both bees and hoverflies show a positive relationship between size and peak amplitude acceleration. (2) After controlling for individual size, do bees and hoverflies differ in the peak acceleration amplitude achieved during non-flight vibrations? We predict that after accounting for individual size, hoverflies should achieve lower peak acceleration amplitudes than bees (Hymenoptera). (3) Can defence vibrations reach the acceleration required to release pollen from buzz-pollinated flowers? We experimentally determined pollen release in two species of buzz-pollinated flowers subject to defence vibrations by both bees and flies.

\section{Materials and Methods}

\section{Specimen collection}

We collected bees and hoverflies in the summer of 2020 (May-August) in three geographic regions in Scotland: Stirlingshire, the Orkney Isles and the Outer Hebrides. We visited flower-rich sites and collected insects visiting flowers or in surrounding vegetation using insect nets or plastic vials. For each specimen we recorded the location and plant species when collected on flowers. Immediately after capture, insects were placed into individual plastic vials, labelled and stored in a cooler with ice packs for transport. We measured thoracic vibrations of each insect in an indoor lab as soon as possible following collection, usually within $3 \mathrm{hrs}$. 
136 Because we were interested in determining the capacity of insects to transduce vibrations, we measured thoracic vibrations applied by insects onto a calibrated miniature uniaxial piezoelectric accelerometer (0.2 g; 352C23, PCB Piezotronics, Hückelhoven, Germany). The experimental system consisted of the $0.2 \mathrm{~g}$ miniature accelerometer attached to the end of a split bamboo flower stick (3.7mm diameter $\times 200 \mathrm{~mm}$ length, LBS Horticulture, Colne, Lancashire) by $30 \mathrm{~mm}$ of connecting electrical cable (1 $1 \mathrm{~mm}$ diameter, PCB Piezotronics) between the base of the accelerometer and the end of the stick. The cable was attached to the stick with tape (Scotch 810 Magic $^{\mathrm{TM} T a p e, 3 M) . ~ T h e ~}$ stick was held in place by attaching it to a small plastic container through two small holes (Figure 2). Empirical measurement of the vibrational properties of the experimental system indicated a resonant frequency of approximately $17 \mathrm{~Hz}$ (data not shown) and thus below the measured insect vibrations. We did not observe any significant contribution of resonance to the vibrations analysed. resolution (9250; NI, Newbury, UK) on a Compact DAQ chassis (cDAQ-9171, NI) connected to a portable computer (Elitebook 850 G5, HP Inc, Glasgow, UK) through a USB port. We used custommade software written in LabView NXG 5.0 (NI) for signal conditioning and data acquisitions at a sampling rate of $10,240 \mathrm{~Hz}$. The data were stored in the computer as TDMS files ( $\mathrm{NI}$ high throughput file format) to reduce buffer size and preserve acquisition information, and subsequently converted to tab-separated text files for downstream analyses using custom software.

To measure the vibrations transduced by insects onto the accelerometer system, we tethered the chilled insects using a loop placed between head and thorax, made of nylon thread $(0.18 \mathrm{~mm}$ diameter) held at the tip of a metal syringe needle $(1.24 \mathrm{~mm} \times 13 \mathrm{~mm})$ with a blunted end (Pritchard \& Vallejo-Marín 2020b). In some cases, further chilling was required where insects were still very active and we achieved this by briefly placing them in a freezer $\left(-20^{\circ} \mathrm{C}\right)$ until the insect became inactive (1-3 minutes). The tethered insects were then allowed to return to room temperature. Once the insect had fully recovered, we held the base of the syringe needle by hand and gently but firmly pressed the insect's thorax (dorsal surface) against the accelerometer along the axis of vibration measurement of the accelerometer. The insect often begun producing defence vibrations after being pressed against the accelerometer. In some cases, we also induced the production of vibrations by breathing onto the insect. We aimed to record approximately 45 seconds for each insect but the length of the recording varied across individuals. After recording, the insects were freeze-killed by placing then at $-20^{\circ} \mathrm{C}$ overnight. 
Insects were pinned, air dried, and identified with the help of taxonomic and field keys (Stubbs \& Falk 2002, Ball \& Morris 2015, Falk \& Lewington 2015). To obtain an estimate of thorax size across bees and hoverflies, we used thorax width measured at the widest point with a digital calliper (0.01mm precision; CD-6"CSX, Mitutoyo Inc, Japan). In bees, body mass and intertegular distance are positively correlated (Cane 1987), and thorax width should be positively correlated with intertegular distance. We chose this measure in flies as well in order to (1) obtain a trait directly comparable trait between bees and flies, and (2) because we were interested in the vibrations produced by the thoracic muscles, which are responsible for both powering flight and for producing defence and floral vibrations (Pritchard \& Vallejo-Marín 2020a).

We conducted a small experiment to qualitatively determine the capacity of hoverflies to remove pollen from buzz-pollinated flowers with poricidal anthers. We used two species of nectarless, buzzpollinated plants for this experiment. The first was Solanum dulcamara, a perennial plant native to the British Isles with small flowers (15mm across) and five anthers of similar size (4-5mm in length) fused to form a cone at the centre of the corolla. In Europe, S. dulcamara is visited mostly by buzzpollinating Bombus spp., and, occasionally, hoverflies, which probe the base of the corolla and anther cone (Müller 1883, Macior 1964, Free 1970, Waser et al. 2011). Flowers of S. dulcamara were obtained from an experimental plant grown from seeds collected in Stirling, United Kingdom. The second species was S. rostratum, an annual species native to Mexico and the southern U.S.A., but which occurs outside its native range as a noxious weed. The flowers of $S$. rostratum are larger (34mm across), with four anthers presented loosely in the centre of the flower (7.5 $\mathrm{mm}$ in length), and a fifth, enlarged $(12.2 \mathrm{~mm})$, S-shaped anther located off the central axis of the flower (VallejoMarin et al. 2014). In the native range, S. rostratum is visited by a taxonomically and morphologically diverse range of bees, including bumblebees, honeybees and occasionally hoverflies (Linsley \& Cazier 1963, Bowers 1975, Solis-Montero et al. 2015, Vega-Polanco et al. 2020). Experimental populations in Scotland are frequently visited by bumblebees (De Luca et al. 2014), and occasionally by hoverflies (MVM pers. obs.). The flowers of S. rostratum used in this experiment were obtained from two accessions from either the native (10s71, San Miguel de Allende, Mexico; 20.901 ${ }^{\circ}$, $\left.100.705^{\circ}\right)$ or introduced ranges (10-TON-1, Tongzhou, China; $\left.39.451^{\circ}, 116.435^{\circ}\right)$. one of their legs between two fingers, and gently pressing the insect against the anthers of buzz- 
the time. For S. dulcamara we pressed the thorax of the insect against the fused anther cone. For $S$. rostratum we pressed the insect's thorax against the centrally located, four small anthers (feeding anthers). The insect was pressed against the anthers for about 3-5 seconds, in which it produced several defence buzzes. Pollen ejected from the anthers was caught in a small amount of fuchsineglycerol gelatine placed on a microscope slide placed $\sim 10 \mathrm{~mm}$ from the anthers tips (Kearns \& Inouye 1993). Similar manipulation of the anthers using a dead insect did not eject pollen. The presence of pollen grains on the slide was assessed using a compound microscope (CX31, Olympus, Southendon-Sea, Essex). Due to the very large number of pollen grains expelled in most cases, we categorised each slide into one of three classes: no-pollen grains, $<2,000$ grains, and $>2,000$ grains.

\section{Analysis of vibrations}

We used a $20 \mathrm{~Hz}$ high-pass filter (Hanning window, window length=512 samples) on the recordings to remove low-frequency background noise using the fir function of the package seewave (Sueur et al. 2008) in $R$ ver. 4.0.2 (R Core Development Team 2020). From each recording of each insect, we manually selected approximately 10 buzzes. This was carried out blind to the identity of the insect, avoiding introduction of any subconscious bias. A buzz was defined either as a discrete burst of vibration or, in cases where insects produced a continuous buzz for several seconds, we selected a section of it. Buzzes were chosen to capture events of full contact of the insect against the accelerometer, and to sample throughout the duration of the recording. We calculated peak acceleration amplitude $\left(A_{P E A K}\right)$ for each buzz. We first obtained the amplitude envelope of each buzz using the seewave function env, and a smoothing function with a window size of 2 samples. We chose to study smoothed peak amplitude instead of other measurements of amplitude such as root mean squared acceleration (RMS) or non-smoothed peak acceleration because it captures the maximum accelerations produced by the insects, while removing potential artefactual spikes in the recording (Pritchard \& Vallejo-Marín 2020b). However, preliminary analyses showed that, as expected, our chosen smoothed peak acceleration was strongly and positively correlated with RMS acceleration (Pearson's $r=0.788, P<0.001$ ) and with non-smoothed peak acceleration ( $r=0.971$, $P<0.001)$. We also estimated the fundamental frequency of each buzz using the function fund using a window length of 1,024 samples, an overlap of $50 \%$, and a maximum frequency of $1,000 \mathrm{~Hz}$. The median fundamental frequency of the windowed analysis was calculated for each buzz and used for downstream analyses.

\section{Statistical analyses}

We used linear mixed effects models implemented in the package Imer (Bates et al. 2014) in $R$ ver. 4.0.2 (R Development Core Team 2020). We used peak acceleration amplitude ( $\left.A_{\text {PEAK }}\right)$ as the 
response variable, sex, thorax width, order (Hymenoptera or Diptera) and their second and third order interactions as fixed effects, and species and individual as random effects. During model selection, we sequentially removed third order and second order interaction terms that were not statistically significant as assessed by a likelihood ratio test (LRT), while keeping all the main fixed effects. We analysed fundamental frequency of the thoracic vibrations (in $\mathrm{Hz}$ ) using the same approach. The statistical significance of fixed effects was assessed using Type III sums of squares in the $R$ package ImerTest (Kuznetsova et al. 2014). Model predictions for the fixed effects were plotted using the package sjPlot (Lüdeke 2018). A preliminary analysis using only taxa for which we had at least one male and one female individual per species (20 taxa), generated the same conclusions as the analysis of the entire data set (42 taxa), and we therefore report here only the results obtained with the whole data set.

\section{Diversity of insects sampled}

We collected 318 insects in total representing 44 taxa: 113 individuals from 22 taxa of Diptera and 205 individuals from 22 taxa of Hymenoptera. Insects were identified to species in most cases, except for four bee taxa that were identified as morpho species to genus level only (Andrena sp. 1, Andrena sp. 2, Colletes sp. and Lasioglossum sp.). Individuals of the Bombus terrestris/B. lucorum/B. cryptarum/B. magnus species complex were treated as a single taxon (B. terrestris-lucorum) as identification of female workers in this complex using morphological characters is prone to error. A single individual of a hoverfly-mimic conopid fly, Conops quadrifasciata (Conopidae) was caught. For the remaining individuals, all Diptera belonged to the family Syrphidae, and Hymenoptera to the families Andrenidae (3 species), Apidae (17 species), Colletidae (1 species), Halictidae (1 species) and Megachillidae (2 species). On average we sampled 7.2 individuals per species (median 6, range 129). Individuals that did not buzz (number of individuals relative to the total collected for that species), were: 1/1 Conops quadrifasciata, 1/18 Episyrphus balteatus, 1/1 Eristalis arbustorum, 4/10 Helophilus pendulus, 1/6 Rhingia campestris, 1/8 Andrena scotica, 7/11 Apis mellifera, 1/13 Bombus pascuorum, 1/3 Lasioglossum sp., and 1/2 Osmia bicornis. We were able to acquire thoracic vibrations for 299 individuals from 42 taxa (Table 1, Table S1). In total, we obtained vibrations from 94 male and 205 female individuals, including 11 bumblebee queens. Among bees, the bestrepresented taxonomic group was bumblebees (Bombus spp.) with 166 individuals from 13 taxa, including two cuckoo bumblebees, B. bohemicus and B. sylvestris, and two geographically restricted forms collected from the Outer Hebrides, which were treated as separate taxa (B. muscorum agricolae and $B$. jonellus hebridensis). Thorax size for $2 / 16$ individuals of $B$. hypnorum was not 
collected and the specimens lost. At the genus level, all the bees analysed here are reported to buzzpollinate, with the exception of the honeybee, Apis mellifera (Cardinal et al. 2018). In contrast, none of the studied fly species has been reported to buzz-pollinate.

\section{Insect thoracic vibrations}

Figure 3 shows an example of recorded vibrations for two species of bees (Bombus muscorum and Megachile willughbiella) and two species of hoverflies (Volucella bombylans and Episyrphus balteatus) of contrasting thorax size. We analysed 3,918 non-flight thoracic vibrations (defence buzzes) in total, with 13.10 defence buzzes on average per individual (median=10 buzzes, range 150). Defence buzzes produced by bees and flies ranged widely in both amplitude (mean $V_{\text {PEAK }}=123.7 \mathrm{~ms}^{-2}$, range $=2-588 \mathrm{~ms}^{-2}$ ) and fundamental frequency ( $m$ ean $=206 \mathrm{~Hz}$, range $=28-465$ ) (Table 1; Figure 4). Although in many cases the fundamental frequency also corresponded to the dominant frequency (Figure 3F-H), some recordings showed dominant frequencies at higher harmonics (Figure 3E).

For peak acceleration ( $A_{\text {PEAK }}$ ), we did not detect significant third or second order interactions among the fixed effects (sex, size and insect Order) ( $p$-values $>0.05$ as assessed by LRT). In the final model, we observed a significant positive effect of thorax size on $A_{\text {PEAK }}$ (coefficient=42.415, $p$ value $<0.001$; Figure 5, Table 2) but a negative effect of sex, with males producing on average lower amplitude vibrations than females (coefficient=-16.406, $p$-value=0.019). In contrast, both bees and hoverflies produced similar acceleration amplitudes after accounting for sex and thorax size (coefficient for insect Order=-12.892, $p$-value=0.165; Figure 5). In the case of fundamental frequency, we detected a significant interaction between thorax size and insect Order (LRT $p$ value $<0.001$ ) and thus the final selected model preserved this second-order term. Analysis of this model showed that the fundamental frequency of non-flight vibrations differed significantly between bees and hoverflies with the latter producing on average higher-frequency vibrations (coefficient=-190.604, $p$-value<0.001). The effect of thorax size on fundamental frequency differed between bees and hoverflies (Table 2). For hoverflies, increased thorax size was associated with lower frequency vibrations, while in bees, thorax size showed a shallow, positive association with vibration frequency (Figure 5). In contrast to the pattern observed for APEAK, there was no effect of sex on the fundamental frequency of thoracic vibrations (coefficient for males $=-0.969, p$ value $=0.909$ ) . 
297

298

299

300

301

302

303

304

305

306

307

308

309

310

311

312

313

314

315

316

317

318

319

320

321

322

323

324

325

Pollen release

For this experiment we were able to qualitatively assess pollen release in 48 flowers of buzzpollinated Solanum dulcamara ( $n=16$ flowers) and S. rostratum ( $n=17$ and $n=15$, for accessions 12 TON-1 and 10-s-71, respectively). We analysed 12 hoverflies from four species: Platycherius albimanus ( $n=1$ individual), Syrphus vitripennis $(n=3)$, S. ribesii $(n=2)$, Eristalis pertinax $(n=5)$, and Volucella pellucens $(n=1)$. Thorax size of the hoverflies tested varied from $1.80 \mathrm{~mm}$ (P. albimanus) to $5.24 \mathrm{~mm}$ (V. pellucens). We also obtained pollen release samples from 5 bees in four taxa: Lasioglossum sp. $(\mathrm{n}=1)$, Colletes $s p$. $(\mathrm{n}=2)$, Bombus lapidarius $(\mathrm{n}=1$, male), and B. sylvestris $(\mathrm{n}=1$, male). Thorax size in these bees varied from $2.59 \mathrm{~mm}$ (Lasioglossum sp.) to $5.14 \mathrm{~mm}$ (Bombus sylvestris). In the majority of cases (39/48 flowers), defence buzzes by both flies and bees resulted in significant amounts of pollen ejected (well in excess of 2,000 grains). In 2/48 flowers no pollen was released (S. vitripennis on S. rostratum, and B. sylvestris on S. dulcamara), and in $7 / 48$ cases $<2,000$ pollen grains were ejected (flies on both S. dulcamara and S. rostratum).

\section{Discussion}

\section{Buzz-pollinating bees}

Our study shows that even within bees there is a wide range of variation in the non-flight thoracic vibrations produced. Although variation in buzz frequency among bee species is known from acoustic studies of buzz pollination (Burkart et al. 2011, De Luca et al. 2019, Rosi-Denadai et al. 2020), much less is known about variation in vibration amplitude. The lowest peak amplitude among bees was produced by Apis mellifera (Table 1, Figure 6), consistent with the study of King \& Buchmann (2003) that determined that honeybee vibrations cannot reach the acceleration required to remove pollen from the poricidal flowers of Solanum and kiwifruit (Actinidia deliciosa). Similarly, Megachille willoughbiela and $O$. bicornis (Megachilidae) produced relatively low acceleration amplitudes but above those expected to remove pollen from flowers (King \& Buchmann 2003). Regarding these two species, $M$. willoughbiella has been observed buzz-pollinating tomato flowers (Teppner 2005), while some species of Osmia but not O. bicornis, can buzz pollinate (Cane 2014). All remaining bee species in this study produce thoracic vibrations with acceleration amplitudes well above those required to remove pollen from buzz-pollinated flowers (King \& Buchmann 2003, Kemp \& Vallejo-Marin 2020). 
327 Vibrations are not the only way to extract pollen from poricidal anthers (Buchmann 1983). For example, Megachile addenda rubs the poricidal anthers of cranberry (Vaccinium subg. Oxycoccus, Ericaceae) with the forelegs to release pollen, while Osmia ribifloris and Apis mellifera tap anthers of cranberry or blueberry (Vaccinium sect. Cyanococcus) (Thorp 2000). Some bees (e.g., A. mellifera) and hoverflies probe the anther pore with their proboscis or gather pollen previously ejected by buzz-pollinators (Müller 1883, Solis-Montero et al. 2015, Vega-Polanco et al. 2020). Well-known non-buzzing pollen thieves, e.g., Trigona spp., can also chew through the anther wall to access pollen (Renner 1983). In Europe, relatively common hoverflies including Eristalis tenax, Syritta pipiens, Sphaeorphoria sp., and Melanostoma mellinum collect pollen from flowers of Solanum tuberosum and S. nigrum, and Rhingia rostrata visits flowers of Solanum dulcamara probing the anther pores with its mouthparts (Müller 1883). However, vibrating anthers remains unrivalled as an extremely rapid and effective mechanism for removing large amounts of pollen (Harder \& Barclay 1994, Vallejo-Marin et al. 2009, Kemp \& Vallejo-Marin 2020).

\section{Why is buzz pollination so rare in hoverflies?}

If hoverflies can produce buzzes of similar acceleration amplitude as buzz pollinating bees, and as we have shown, defence buzzes by hoverflies as small as $1.80 \mathrm{~mm}$ in thorax width can remove pollen from buzz-pollinated flowers, why don't more hoverflies use vibrations on flowers? There are a number of non-mutually exclusive hypotheses that can explain the lack of buzz-pollinating hoverflies (summarised in Table 3). These hypotheses can be broadly classified into mechanical, behavioural and life history explanations. We have shown that most of the studied bees and hoverflies are capable of producing vibrations of sufficient amplitude to remove pollen, and that the peak acceleration of these vibrations increases with insect size, providing little support for the amplitude limitation mechanical hypothesis. Other mechanical explanations include the hypothesis that flies lack the morphology required to firmly grasp the flower while producing non-flight thoracic vibrations. Bees use their mandibles to hold on to the anthers or other floral tissues while vigorously shaking. The vibrations are then transmitted to the flower by direct contact of the thorax, abdomen, head and to a much lesser extent, the legs (King \& Buchmann 2003). It is possible that a weak attachment to the flower prevents mandible-less flies from holding on to the flowers firmly enough to allow efficient transmission of the vibrations from the thorax to the anthers. Although the fly can hold on to the anthers with its legs, the jointed nature of arthropod legs may make them much poorer channels to transmit vibrations to the substrate (King \& Buchmann 2003, Cocroft \& Rodríguez 2005). 

a behaviour (thoracic vibrations) from one context (e.g. defence) to another (pollen removal). We consider this hypothesis unlikely, given the behavioural flexibility of flies in other contexts (Penney et al. 2014), although there is no direct experimental evidence showing that flies can learn to buzz pollinate. Additionally, lack of buzz-pollinating hoverflies may be explained through an optimal foraging/energetics hypothesis. Producing thoracic vibrations is an energetically costly behaviour (Casey et al. 1985, King et al. 1996), compared to, for example, probing the anther pores with the mouth parts. Even within bumblebees, pollen collection without buzzing seems to be preferred when pollen can be efficiently extracted via other means, which suggests that buzzing is costly (Switzer et al. 2019). If the energetic investment required to produce floral vibrations offsets the fitness returns of releasing large amounts of pollen from a single flower, then floral vibrations will not represent an optimal foraging strategy (Harder 1990). Finally, it could be hypothesised that producing floral vibrations also accrues non-energetic costs. A by-product of floral vibrations is the characteristic high-pitched noise that gives the name to buzz pollination. This sound can be heard at a distance and is possible that buzzing is disadvantageous if it gives away the position of floral visitors to potential predators. Yet, given that buzzing is an alarm or aposematic signal in bees and many hoverflies are Batesian mimics of bees and wasps (Rashed et al. 2009, Moore \& Hassall 2016), selection for silent floral visitors appears unlikely. pollinating hoverflies. Differences in the pollen requirements between bees and flies during larval development might select for very different strategies to remove pollen from flowers. Hoverfly larvae rely mostly on non-pollen nutrition for their development, parasitising other insects, inhabiting environments that are rich in other organic matter, or in some cases parasitising the nests of other bees including social bees and consuming bee-collected resources (Schmid-Hempel 1995, McAlister 2017). In contrast bees collect large amounts of pollen to transport back to their nest and provide food for developing larvae (Müller et al. 2006). The higher pollen requirement in bees favour strategies that allow them to rapidly collect large amounts of pollen from flowers such as producing floral vibrations, while hoverflies are not under similar selective pressures (provisioning of young hypothesis). This hypothesis also predicts that bees that do not regularly collect large amounts of pollen, including social parasites (e.g., cuckoo bumblebees), male bees, and other exceptional bees should not deploy vibrations to remove pollen from flowers despite possessing the potential to produce vibrations of sufficient amplitude. Our study shows that species of obligate social parasites (cuckoo bumblebees $B$. sylvestris and B. bohemicus), which lack corbiculae and rely on the host workers to collect pollen and nectar for larval feeding (Lhomme \& Hines 2019), produced vibrations 
with similar high acceleration amplitude to those used by buzz-pollinating bumblebees on flowers (Arroyo-Correa et al. 2019). Similarly, although male bees reached lower acceleration than females, both sexes of most bee species are able to generate vibrations capable of removing pollen from buzz-pollinated flowers (King \& Buchmann 2003, Kemp \& Vallejo-Marin 2020).

Our study has shown that hoverflies are capable of producing defence vibrations with similar acceleration amplitude to buzz-pollinating bees, and that these vibrations are sufficient to remove pollen from different species of buzz-pollinated flowers. We believe that differences in pollen requirements between bees and hoverflies provide a compelling hypothesis for the dearth of buzzpollinating flies. However, additional work is required to explicitly address this and other explanations for the difference in buzz-pollination capacity among flies and bees. Moreover, the question of why some bees, but not others, buzz-pollinate remains unanswered. Further comparisons of buzz-pollinating and non-buzz-pollinating bees with different morphologies, behaviours, and life histories could help addressing this question.

\section{Acknowledgements}

We thank P. De Luca and S. Buchmann for constructive comments on a previous version of the manuscript, and L.C. Vallejo and L.E. Vallejo for assistance in collecting insects. This research was supported by The Leverhulme Trust (RPG-2018-235).

\section{References}

Arroyo-Correa, B., C. E. Beattie \& M. Vallejo-Marin (2019) Bee and floral traits affect the characteristics of the vibrations experienced by flowers during buzz-pollination. Journal of Experimental Biology, 222, jeb198176.

Ball, S. \& R. Morris (2015) Britain's Hoverflies: A Field Guide, Second Edition edn. Woodstock, Oxfordshire: Princeton University Press.

Bates, D., M. Maechler \& B. Bolker, (2014) Ime4: Linear mixed-effects models using Eigen and S4_. R package version 1.1-7. http://CRAN.R-project.org/package=Ime4.

Bowers, K. A. W. (1975) The pollination ecology of Solanum rostratum (Solanaceae). American Journal of Botany, 62, 633.

Buchmann, S. L., (1983) Buzz pollination in angiosperms. In: Handbook of Experimental Pollination Biology: 73. C. E. Jones \& R. J. Little (Eds.). Scientific and Academic Editions, NY.

Buchmann, S. L. \& J. P. Hurley (1978) Biophysical model for buzz pollination in Angiosperms. Journal of Theoretical Biology, 72, 639.

Buchmann, S. L., C. E. Jones \& L. J. Colin (1977) Vibratile pollination of Solanum douglasii and Solanum xanti (Solanaceae) in Southern California USA. Wasmann Journal of Biology, 35, 1.

Burkart, A., K. Lunau \& C. Schlindwein (2011) Comparative bioacoustical studies on flight and buzzing of neotropical bees. Journal of Pollination Ecology, 6, 118.

Cane, J. H. (1987) Estimation of bee size using intertegular span (Apoidea). Journal of the Kansas Entomological Society, 60, 145.

Cane, J. H. (2014) The oligolectic bee Osmia brevis sonicates Penstemon flowers for pollen: a newly documented behavior for the Megachilidae. Apidologie, 45, 678. 
Cardinal, S., S. L. Buchmann \& A. L. Russell (2018) The evolution of floral sonication, a pollen foraging behavior used by bees (Anthophila). Evolution, 72, 590.

Casey, T. M., M. L. May \& K. R. Morgan (1985) Flight energetics of euglossine bees in relation to morphology and wing stroke frequency. Journal of Experimental Biology, 116, 271.

Cocroft, R. B. \& R. L. Rodríguez (2005) The behavioral ecology of insect vibrational communication. AIBS Bulletin, 55, 323.

Conrad, T. \& M. Ayasse (2015) The role of vibrations in population divergence in the red mason bee, Osmia bicornis. Current Biology, 25, 2819.

Cook, D. F., S. C. Voss, J. T. Finch, R. C. Rader, J. M. Cook \& C. J. Spurr (2020) The role of flies as pollinators of horticultural crops: An Australian case study with worldwide relevance. Insects, 11, 341.

Danforth, B. N., R. L. Minckley, J. L. Neff \& F. Fawcett (2019) The solitary bees: biology, evolution, conservation. Princeton University Press.

De Luca, P. A., S. Buchmann, C. Galen, A. C. Mason \& M. Vallejo-Marin (2019) Does body size predict the buzz-pollination frequencies used by bees? Ecology and Evolution, 9, 4875.

De Luca, P. A., L. F. Bussiere, D. Souto-Vilaros, D. Goulson, A. C. Mason \& M. Vallejo-Marín (2013) Variability in bumblebee pollination buzzes affects the quantity of pollen released from flowers. Oecologia, 172, 805.

De Luca, P. A., D. A. Cox \& M. Vallejo-Marín (2014) Comparison of pollination and defensive buzzes in bumblebees indicates species-specific and context-dependent vibrations. Naturwissenschaften, 101, 331.

De Luca, P. A. \& M. Vallejo-Marin (2013) What's the 'buzz' about? The ecology and evolutionary significance of buzz-pollination. Curr Opin Plant Biol, 16, 429.

Dickinson, M. H., F. O. Lehmann \& W. P. Chan (1998) The control of mechanical power in insect flight. American Zoologist, 38, 718.

Falk, S. \& R. Lewington (2015) Field Guide to the Bees of Great Britain and Ireland. United Kingdom: Bloomsbury Publishing.

Free, J. (1970) The flower constancy of bumblebees. The Journal of Animal Ecology, 395.

Harder, L. D. (1990) Behavioral responses by bumble bees to variation in pollen availability. Oecologia, 85, 41.

Harder, L. D. \& M. R. Barclay (1994) The functional significance of poricidal anthers and buzz pollination: controlled pollen removal from Dodecatheon. Functional Ecology, 8, 509.

Holloway, B. A. (1976) Pollen-feeding in hover-flies (Diptera: Syrphidae). New Zealand Journal of Zoology, 3, 339.

Hrncir, M., F. G. Barth \& J. Tautz, (2005) Vibratory and airborne-sound signals in bee communication (Hymenoptera). In: Insect sounds and communication: physiology, behaviour, ecology, and evolution: 421.

Hrncir, M., C. Maia-Silva, S. I. Mc Cabe \& W. M. Farina (2011) The recruiter's excitement - features of thoracic vibrations during the honey bee's waggle dance related to food source profitability. Journal of Experimental Biology, 214, 4055.

Inouye, D. W., B. M. Larson, A. Ssymank \& P. G. Kevan (2015) Flies and flowers III: ecology of foraging and pollination. Journal of Pollination Ecology, 16, 115.

Kearns, C. A. \& D. W. Inouye (1993) Techniques for Pollination Biologists. Niwot, Colorado: University Press of Colorado.

Kemp, J. E. \& M. Vallejo-Marin (2020) Pollen dispensing schedules in buzz-pollinated plants: Experimental comparison of species with contrasting floral morphologies. bioRxiv, 10.1101/2020.08.04.235739.

Kevan, P. \& H. Baker (1983) Insects as flower visitors and pollinators. Annual review of entomology, 28, 407. 
King, M. J. \& S. L. Buchmann (2003) Floral sonication by bees: Mesosomal vibration by Bombus and Xylocopa, but not Apis (Hymenoptera: Apidae), ejects pollen from poricidal anthers. Journal of the Kansas Entomological Society, 76, 295.

King, M. J., S. L. Buchmann \& H. Spangler (1996) Activity of asynchronous flight muscle from two bee families during sonication (buzzing). Journal of Experimental Biology, 199, 2317.

Kirchner, W. \& J. Röschard (1999) Hissing in bumblebees: an interspecific defence signal. Insect Soc, 46, 239.

Konzmann, S., M. Kluth, D. Karadana \& K. Lunau (2019) Pollinator effectiveness of a specialist bee exploiting a generalist plant-tracking pollen transfer by Heriades truncorum with quantum dots. Apidologie, 1.

Kuznetsova, A., P. B. Brockhoff \& R. H. B. Christensen, (2014) ImerTest: Tests for random and fixed effects for linear mixed effect models (Imer objects of Ime4 package). R package version 2.06.

Larson, B., P. Kevan \& D. W. Inouye (2001) Flies and flowers: taxonomic diversity of anthophiles and pollinators. The Canadian Entomologist, 133, 439.

Lhomme, P. \& H. M. Hines (2019) Ecology and evolution of cuckoo bumble Bees. Ann Entomol Soc Am, 112, 122.

Linsley, E. \& M. A. Cazier (1963) Further observations on bees which take pollen from plants of the genus Solanum. Pan-Pacific Entomologist, 39, 1.

Lüdeke, D., (2018) sjPlot: Data Visualization for Statistics in Social Science, https://CRAN.Rproject.org/package=sjPlot.

Macior, L. W. (1964) Experimental study of floral ecology of Dodecatheon meadia. American Journal of Botany, 51, 96.

McAlister, E. (2017) The Secret Life of Flies. Natural History Museum London.

Michener, C. D. (1962) An interesting method of pollen collecting by bees from flowers with tubular anthers. Revista de Biologia Tropical, 10, 167.

Moore, C. D. \& C. Hassall (2016) A bee or not a bee: an experimental test of acoustic mimicry by hoverflies. Behavioral Ecology, 27, 1767.

Müller, A., S. Diener, S. Schnyder, K. Stutz, C. Sedivy \& S. Dorn (2006) Quantitative pollen requirements of solitary bees: Implications for bee conservation and the evolution of beeflower relationships. Biological Conservation, 130, 604.

Müller, H. (1883) The Fertilisation of Flowers. London: Macmillan.

Nunes-Silva, P., G. D. Cordeiro, D. Obregon, J. F. L. Neto, F. C. Thompson, B. F. Viana, B. M. Freitas \& P. G. Kevan (2010) Pollenivory in larval and adult flower flies: Pollen availability and visitation rate by Toxomerus politus SAY (Diptera: Syrphidae) on sorghum Sorghum bicolor (L.) MOENCH (Poaceae). Stud Dipterologica, 17, 177.

Penney, H. D., C. Hassall, J. H. Skevington, B. Lamborn \& T. N. Sherratt (2014) The relationship between morphological and behavioral mimicry in hover flies (Diptera: Syrphidae). The American Naturalist, 183, 281.

Portman, Z. M., M. C. Orr \& T. Griswold (2019) A review and updated classification of pollen gathering behavior in bees (Hymenoptera, Apoidea). Journal of Hymenoptera Research, 71, 171.

Pritchard, D. J. \& M. Vallejo-Marín (2020a) Buzz pollination. Current Biology, 30, R858.

Pritchard, D. J. \& M. Vallejo-Marín (2020b) Floral vibrations by buzz-pollinating bees achieve higher frequency, velocity and acceleration than flight and defence vibrations. The Journal of Experimental Biology, jeb.220541.

Rashed, A., M. I. Khan, J. W. Dawson, J. E. Yack \& T. N. Sherratt (2009) Do hoverflies (Diptera: Syrphidae) sound like the Hymenoptera they morphologically resemble? Behavioral Ecology, 20, 396.

Renner, S. S. (1983) The widespread occurence of anther destruction by Trigona bees in Melastomataceae. Biotropica, 15, 251. 
Rick, C. M. (1950) Pollination relations of Lycopersicon esculentum in native and foreign regions. Evolution, 4, 110.

Rosi-Denadai, C. A., P. C. S. Araujo, L. A. O. Campos, L. Cosme, Jr. \& R. N. C. Guedes (2020) Buzzpollination in Neotropical bees: genus-dependent frequencies and lack of optimal frequency for pollen release. Insect Science, 27, 133.

Russell, A. L., S. L. Buchmann \& D. R. Papaj (2017) How a generalist bee achieves high efficiency of pollen collection on diverse floral resources. Behavioral Ecology, 28, 991.

Schmid-Hempel, P. (1995) Parasites and social insects. 26, 255.

Solis-Montero, L., C. H. Vergara \& M. Vallejo-Marin (2015) High incidence of pollen theft in natural populations of a buzz-pollinated plant. Arthropod-Plant Inte, 9, 599.

Stubbs, A. E. \& S. J. Falk (2002) British Hoverflies, Second Edition edn. Dorchester, Dorset, U.K.: The Dorset Press.

Sueur, J., T. Aubin \& C. Simonis (2008) Seewave, a free modular tool for sound analysis and synthesis. Bioacoustics, 18, 213.

Switzer, C. M., A. L. Russell, D. R. Papaj, S. A. Combes \& R. Hopkins (2019) Sonicating bees demonstrate flexible pollen extraction without instrumental learning. Current Zoology, 65, 425.

Team, R. D. C., (2020) R. A language and environment for statistical computing. R Foundation for Statistical Computing, Vienna, Austria. URL http://www.R-project.org.

Teppner, H. (2005) Pollinators of tomato, Solanum lycopersicum (Solanaceae), in central Europe. PHYTON-HORN-, 45, 217.

Thorp, R. W. (1979) Structural, behavioral, and physiological adaptations of bees (Apoidea) for collecting pollen. Annals of the Missouri Botanical Garden, 66, 788.

Thorp, R. W. (2000) The collection of pollen by bees. Plant Systematics and Evolution, 222, 211.

Vallejo-Marin, M. (2019) Buzz pollination: studying bee vibrations on flowers. New Phytologist, 224, 1068.

Vallejo-Marin, M., J. S. Manson, J. D. Thomson \& S. C. H. Barrett (2009) Division of labour within flowers: heteranthery, a floral strategy to reconcile contrasting pollen fates. Journal of Evolutionary Biology, 22, 828.

Vallejo-Marin, M., C. Walker, P. Friston-Reilly, L. Solis-Montero \& B. Igic (2014) Recurrent modification of floral morphology in heterantherous Solanum reveals a parallel shift in reproductive strategy. Philosophical Transactions of the Royal Society B-Biological Sciences, 369, 20130256.

Vega-Polanco, M., L. A. Rodríguez-Islas, R. Y. Escalona-Domenech, L. Cruz-López, J. C. Rojas \& L. SolísMontero (2020) Does florivory affect the attraction of floral visitors to buzz-pollinated Solanum rostratum? Arthropod-Plant Inte, 14, 41.

Waser, N. M., J. Ollerton \& A. Erhardt (2011) Typology in pollination biology: lessons from an historical critique. Journal of Pollination Ecology, 3, 1.

Woodcock, T. S., B. M. Larson, P. G. Kevan, D. W. Inouye \& K. Lunau (2014) Flies and flowers II: floral attractants and rewards. Journal of Pollination Ecology, 12, 63. 
Table 1. Summary statistics of the characteristics of non-flight thoracic vibrations (defence buzzes) and thorax size from 299 individuals in 42 taxa of

574 hoverflies (Syrphidae) and bees (Hymenoptera: Apoidea: Anthophila). Number of buzzes analysed: N=3,918 buzzes. Mean \pm SE.

\begin{tabular}{lccccc}
\hline Species & $\begin{array}{c}\text { Peak amplitude } \\
\left(\mathbf{m ~ s}^{-2}\right)\end{array}$ & $\begin{array}{c}\text { Fundamental Frequency } \\
(\mathbf{H z})\end{array}$ & $\begin{array}{c}\mathbf{N} \\
\text { buzzes }\end{array}$ & $\begin{array}{c}\text { Thorax width } \\
(\mathbf{m m})\end{array}$ & $\begin{array}{c}\mathbf{N} \\
\text { bees }\end{array}$ \\
\hline Diptera & $152.89 \pm 15.37$ & $297.2 \pm 29.87$ & 100 & $3.86 \pm 1.29$ & 10 \\
\hline Cheilosia illustrata & $44.09 \pm 5.23$ & $225.17 \pm 26.72$ & 72 & $3.52 \pm 2.49$ & 3 \\
\hline Epistrophe grossulariae & $59.05 \pm 4.16$ & $320.89 \pm 22.63$ & 202 & $2.42 \pm 0.61$ & 17 \\
\hline Episyrphus balteatus & $144.96 \pm 27.4$ & $190.84 \pm 36.06$ & 29 & $3.69 \pm 2.61$ & 3 \\
\hline Eristalis horticola & $117.86 \pm 25.72$ & $210.91 \pm 46.03$ & 22 & $4.14 \pm 4.14$ & 2 \\
\hline Eristalis interruptus & $71.23 \pm 23.74$ & $178.19 \pm 59.4$ & 10 & 4.23 & 1 \\
\hline Eristalis intricarius & $153.95 \pm 15.17$ & $211.09 \pm 20.8$ & 104 & $3.96 \pm 1.32$ & 10 \\
\hline Eristalis pertinax & $35.78 \pm 8.21$ & $233.58 \pm 53.59$ & 20 & 3.16 & 1 \\
\hline Ferdinandia cuprea & $79.83 \pm 8.19$ & $225.93 \pm 23.18$ & 96 & $3.65 \pm 1.63$ & 6 \\
\hline Helophilus pendulus & $149.39 \pm 49.8$ & $223.62 \pm 74.54$ & 10 & 3.50 & 1 \\
\hline Leucozona lucorum & $139.27 \pm 16.77$ & $196.94 \pm 23.71$ & 70 & $4.83 \pm 2.41$ & 5 \\
\hline Merodon equestris & $62 \pm 11.72$ & $140.8 \pm 26.61$ & 29 & 3.96 & 1 \\
\hline Myathropa florea & $51.06 \pm 5.6$ & $275.1 \pm 30.2$ & 84 & $1.64 \pm 0.73$ & 6 \\
\hline Platycheirus albimanus & $96.62 \pm 14.57$ & $249.29 \pm 37.58$ & 45 & $3.15 \pm 1.57$ & 5 \\
\hline Rhingia campestris & $97.84 \pm 22.45$ & $281.94 \pm 64.68$ & 20 & $3.66 \pm 3.66$ & 2 \\
\hline Scaeva pyrastris & $151.22 \pm 17.12$ & $177.51 \pm 20.1$ & 79 & $4.57 \pm 2.28$ & 5 \\
\hline Sericomyia silentis & $59 \pm 5.43$ & $300.64 \pm 27.68$ & 119 & $2.75 \pm 0.92$ & 10 \\
\hline Syrphus ribesii & $70.17 \pm 9.14$ & $210.05 \pm 27.35$ & 60 & $2.85 \pm 1.28$ & 6 \\
\hline Syrphus vitripennis & $144.76 \pm 13.27$ & $186.33 \pm 17.08$ & 120 & $5.14 \pm 1.94$ & 8 \\
\hline Volucella bombylans & $176.64 \pm 32.8$ & $140.7 \pm 26.13$ & 30 & $4.79 \pm 3.39$ & 3 \\
\hline Volucella pellucens & & & & & \\
\hline Hymenopte & & & & & \\
\hline
\end{tabular}

Hymenoptera 


\begin{tabular}{|c|c|c|c|c|c|}
\hline Andrena scotica & $128.98 \pm 12.71$ & $150.65 \pm 14.84$ & 104 & $3.60 \pm 1.47$ & 7 \\
\hline Andrena sp. 1 & $96.99 \pm 18.01$ & $138.13 \pm 25.65$ & 30 & $3.40 \pm 3.4$ & 2 \\
\hline Andrena sp. 2 & $99.4 \pm 14.06$ & $163.25 \pm 23.09$ & 51 & $2.99 \pm 1.72$ & 4 \\
\hline Anthophora furcata & $172.33 \pm 57.44$ & $127.8 \pm 42.6$ & 10 & 4.37 & 1 \\
\hline Apis mellifera & $32.55 \pm 4.91$ & $119.26 \pm 17.98$ & 45 & $3.56 \pm 2.05$ & 4 \\
\hline Bombus bohemicus & $153.91 \pm 16.22$ & $199.83 \pm 21.06$ & 91 & $5.27 \pm 2.15$ & 7 \\
\hline Bombus hortorum & $142.7 \pm 9.21$ & $189.46 \pm 12.23$ & 241 & $4.83 \pm 1.17$ & 18 \\
\hline Bombus hypnorum & $141.41 \pm 10.02$ & $222.49 \pm 15.77$ & 200 & $4.76 \pm 1.23$ & 16 \\
\hline Bombus jonellus & $127.42 \pm 13.99$ & $167.58 \pm 18.39$ & 84 & $4.27 \pm 1.74$ & 7 \\
\hline Bombus jonellus hebridensis & $129.32 \pm 9.83$ & $180.3 \pm 13.71$ & 174 & $4.05 \pm 1.17$ & 13 \\
\hline Bombus lapidarius & $125.35 \pm 8.76$ & $207.37 \pm 14.48$ & 206 & $4.57 \pm 1.14$ & 17 \\
\hline Bombus monticola & $125.24 \pm 41.75$ & $191.02 \pm 63.67$ & 10 & 3.95 & 1 \\
\hline Bombus muscorum & $201.98 \pm 15.72$ & $159.65 \pm 12.43$ & 166 & $5.04 \pm 1.35$ & 15 \\
\hline Bombus muscorum agricolae & $193.43 \pm 14.75$ & $220.64 \pm 16.82$ & 173 & $4.73 \pm 1.67$ & 9 \\
\hline Bombus pascuorum & $139.53 \pm 11.92$ & $201.54 \pm 17.22$ & 138 & $4.54 \pm 1.37$ & 12 \\
\hline Bombus pratorum & $101.48 \pm 7.85$ & $194.28 \pm 15.03$ & 168 & $3.88 \pm 1.23$ & 11 \\
\hline Bombus sylvestris & $140.11 \pm 10.68$ & $175.64 \pm 13.39$ & 173 & $5.01 \pm 1.58$ & 11 \\
\hline Bombus terrestris-lucorum & $144.17 \pm 7.46$ & $182.43 \pm 9.45$ & 374 & $5.09 \pm 0.96$ & 29 \\
\hline Colletes sp. & $67.36 \pm 12.73$ & $140.11 \pm 26.48$ & 29 & $3.06 \pm 3.06$ & 2 \\
\hline Lasioglossum sp. & $62.13 \pm 12.96$ & $225.7 \pm 47.06$ & 24 & $2.07 \pm 2.07$ & 2 \\
\hline Megachile willughbiella & $63.31 \pm 7.85$ & $242.72 \pm 30.11$ & 66 & $4.30 \pm 2.15$ & 5 \\
\hline Osmia bicornis & $57.38 \pm 9.19$ & $117.31 \pm 18.78$ & 40 & 4.01 & 1 \\
\hline
\end{tabular}


576 Table 2. Analysis of peak acceleration (A) and fundamental frequency (B) of non-flight thoracic

577 vibrations (defence buzzes). Separate linear mixed-effects models were fitted for each response

578 variable (amplitude or frequency) using species and individual as random effects and insect Order,

579 thorax size and sex as fixed effects. The table shows statistical tests of significance for fixed effects

580 calculated using Type III sums of squares with Satterthwaite's correction. Sample sizes in both

581 models are: 3,884 observations, 296 individuals, and 42 taxa.

582 A. Peak acceleration amplitude $\left(\mathrm{ms}^{-2}\right)$

\begin{tabular}{lrrr}
\hline & \multicolumn{1}{c}{ Estimate } & \multicolumn{1}{c}{ Std. Error } & \multicolumn{1}{c}{$\boldsymbol{p}$-value } \\
\hline Intercept & -37.572 & 15.679 & \\
Order (Hymenoptera) & -12.892 & 9.098 & 0.165 \\
Thorax size (mm) & 42.415 & 4.076 & $<0.001$ \\
Sex (male) & -16.406 & 6.948 & 0.019 \\
\hline
\end{tabular}

583

584

B. Fundamental frequency $(\mathrm{Hz})$

\begin{tabular}{lrrr}
\hline & Estimate & \multicolumn{1}{c}{ Std. Error } & \multicolumn{1}{c}{$\boldsymbol{p}$-value } \\
\hline Intercept & 351.886 & 31.341 & \\
Order (Hymenoptera) & -190.604 & 42.773 & $<0.001$ \\
Thorax size (mm) & -32.857 & 8.417 & 0.011 \\
Sex (male) & -0.970 & 8.509 & 0.909 \\
Order * size & 37.960 & 10.569 & $<.001$ \\
\hline
\end{tabular}

585 
Table 3. Hypotheses explaining why most flies do not use vibrations to remove pollen from flowers with poricidal anthers (buzz-pollinated flowers).

\begin{tabular}{|c|c|c|}
\hline Type & Hypothesis & Brief description \\
\hline \multirow[t]{2}{*}{$\begin{array}{l}\text { Mechanical- } \\
\text { Morphological }\end{array}$} & $\begin{array}{l}\text { Amplitude } \\
\text { limitation }\end{array}$ & $\begin{array}{l}\text { Hoverflies cannot produce vibrations of sufficient amplitude to } \\
\text { release pollen from poricidal anthers. }\end{array}$ \\
\hline & Weak attachment & $\begin{array}{l}\text { Hoverflies, in part because they lack mandibles, cannot hold } \\
\text { onto the flower to transmit thoracic vibrations to the flower } \\
\text { effectively. }\end{array}$ \\
\hline \multirow[t]{3}{*}{ Behavioural } & $\begin{array}{l}\text { Behavioural } \\
\text { inflexibility }\end{array}$ & $\begin{array}{l}\text { Inability to repurpose a behaviour (thoracic vibrations) from } \\
\text { one context (defence) to another (pollen removal). }\end{array}$ \\
\hline & $\begin{array}{l}\text { Energetics/Optimal } \\
\text { foraging }\end{array}$ & $\begin{array}{l}\text { The energy required to produce floral vibrations is more costly } \\
\text { than the benefit from accessing the pollen through vibrations; } \\
\text { sufficient pollen can be removed without producing costly } \\
\text { vibrations. }\end{array}$ \\
\hline & Predator attraction & $\begin{array}{l}\text { The sound of floral vibrations, which can be heard from a few } \\
\text { meters away, may attract potential predators. }\end{array}$ \\
\hline \multirow[t]{2}{*}{ Life History } & $\begin{array}{l}\text { Provisioning of } \\
\text { young }\end{array}$ & $\begin{array}{l}\text { In flies, pollen is consumed by the adults during floral visitation } \\
\text { and used by females before egg laying. In contrast, bees also } \\
\text { have to collect and transport pollen back to their nests to } \\
\text { provide developing larvae. The higher pollen requirement in } \\
\text { bees favour strategies that allow them to rapidly collect and } \\
\text { transport large amounts of pollen, while the same does not } \\
\text { apply in hoverflies. }\end{array}$ \\
\hline & Sociality & $\begin{array}{l}\text { This could be an extension of the Provisioning of young } \\
\text { hypothesis. In social species, pollen provision might exceed the } \\
\text { requirements of a solitary bee, particularly favouring rapid } \\
\text { collection of large amounts of pollen. }\end{array}$ \\
\hline
\end{tabular}


Figure 1. Hoverflies and bees use different strategies to collect pollen from buzz-pollinated flowers.

591 (A) Marmalade hoverfly (Episyrphus balteatus, Syrphidae) gathers pollen from the anther pores

592

593

594

595

596

597

598

599

600

601

602

603

604

605

606

607

608

609

610

611

612

613

614

615

616

617

618

619

620

621

622 using its mouth parts in a flower of buffalo bur (Solanum rostratum, Solanaceae) in Scotland. (B) Buff-tailed bumblebee (Bombus terrestris audax) uses vibrations from its thoracic muscles to rapidly remove large amounts of pollen in an experimental flower of S. rostratum. Photo credits: (A) Phil Friston-Reilly; (B) Mario Vallejo-Marín.

Figure 2. Experimental set up to acquire non-flight thoracic vibrations of bees and flies. Briefly, a chilled insect was tethered between the head and the thorax using a loop made of nylon thread held at the tip of a metal syringe needle with a blunted end. The insect's thorax was gently but firmly pressed against a miniature piezoelectric accelerometer (PCB 352C23) as shown in the diagram. The accelerometer was attached to the end of a split bamboo flower stick by $30 \mathrm{~mm}$ of connecting electrical cable. The cable was attached to the stick with tape. The stick was held in place by attaching it to a plastic container through one hole in each end. The voltage signal generated by the accelerometer was acquired using a CompactDAQ system consisting of a NI chassis (NI cDAQ-9171) and a C-Series input module with 24-bit resolution (NI 9250). The data was recorded on a PC laptop using custom software written in LabView. Full description of the experimental set up is provided in the Materials and Methods section.

Figure 3. Examples of non-flight thoracic vibrations ("defence buzzes") of two species of hoverflies (Diptera: Syrphidae): the large parasitic bumblebee mimic hoverfly, Volucella bombylans (panels A,E) and the small marmalade hoverfly, Episyrphus balteatus (D, H); and two bee species (Hymenoptera: Apidae and Megachillidae): the moss carder bumblebee, Bombus muscorum (B, $F$ ), and the Willoughby's leafcutter bee, Megachile willoughbiella (D, H). Panels A-D show two recorded seconds of defence vibrations in the time domain. A single buzz, or buzz section, selected for subsequent analysis is shown in teal colour. The dotted horizontal line shows the peak amplitude acceleration of the selected buzz. Panels E-H show the selected buzz in the frequency domain, specifically the power spectrum density (PSD). The dashed vertical lines show the harmonic series $(<1 \mathrm{kHz})$ of the fundamental frequency (the first peak in the PSD).

Figure 4. Box-plots showing the within- and among-species variation in peak acceleration amplitude (top panel) and fundamental frequency (bottom panel) of non-flight thoracic vibrations (defence buzzes) in bees (Hymenoptera: Andrenidae, Apidae, Colletidae, Halictidae and Megachillidae) and hoverflies (Diptera: Syrphidae).

Figure 5. Relationship between thorax width and (A) peak acceleration amplitude or (B) fundamental frequency of non-flight thoracic vibrations (defence vibrations) of hoverflies (Diptera, purple) and 
623 bees (Hymenoptera, green). Observed values are shown with closed symbols ( $n=3,884$ buzzes, 296

624 insects, 42 taxa). The lines represent the predicted values (marginal effects) of the response variable

625 (amplitude or frequency) for a range of thorax width values, estimated with linear mixed-effects

626 models. The shaded area corresponds to the $95 \%$ confidence intervals of the predicted values.

627 Figure 6. Relationship between peak acceleration amplitude and thorax width for 42 taxa of

628 hoverflies (Diptera) and bees (Hymenoptera). All the bee genera shown here are known to buzz-

629 pollinate, with the exception of Apis mellifera (Am), while none of the hoverfly genera shown here

630 have been observed buzz-pollinating. The only published observation of a buzz-pollinating fly is for

631 Copestylum mexicanum (formerly Volucella mexicana). Only the mean values are shown for each

632 species. The size of the symbols is proportional to the number of buzzes analysed. Species key:

633 As=Andrena scotica, Asp1=Andrena sp. 1, Asp2=Andrena sp. 2, Af=Anthophora furcata, Am=Apis

634 mellifera, $\mathrm{Bb}=$ Bombus bohemicus, $\mathrm{Bho}=$ Bombus hortorum, Bhy=Bombus hypnorum, $\mathrm{Bj}=$ Bombus

635 jonellus, $\mathrm{Bjh}=$ Bombus jonellus hebridensis, $\mathrm{Bl}=$ Bombus lapidarius, $\mathrm{Bmo}=$ Bombus monticola,

$636 \mathrm{Bm}=$ Bombus muscorum, $\mathrm{Bma}=$ Bombus muscorum agricolae, $\mathrm{Bpa}=$ Bombus pascuorum, $\mathrm{Bpr}=\mathrm{Bombus}$

637 pratorum, $\mathrm{Bs}=$ Bombus sylvestris, $\mathrm{Bt}=$ =Bombus terrestris-lucorum, $\mathrm{Csp}=$ Colletes $\mathrm{sp}$., $\mathrm{Lsp}=$ Lasioglossum

$638 s p ., \mathrm{Mw}=$ Megachile willughbiella, $\mathrm{Ob}=$ Osmia bicornis, $\mathrm{Ci}=$ Cheilosia illustrata, $\mathrm{Eg}=$ Epistrophe

639 grossulariae, Eb=Episyrphus balteatus, Eh=Eristalis horticola, Eip=Eristalis interruptus, Eic=Eristalis

640 intricarius, $\mathrm{Ep}=$ Eristalis pertinax, $\mathrm{Fc}=$ Ferdinandia cuprea, $\mathrm{Hp}=$ Helophilus pendulus, $\mathrm{Ll}=$ Leucozona

641 lucorum, $\mathrm{Me}=$ Merodon equestris, $\mathrm{Mf}=$ Myathropa florea, $\mathrm{Pa}=$ Platycheirus albimanus, $\mathrm{Rc}=$ Rhingia

642 campestris, $\mathrm{Sp}=S c a e v a$ pyrastris, $\mathrm{Ss}=$ Sericomyia silentis, Sr=Syrphus ribesii, Sv=Syrphus vitripennis,

$643 \mathrm{Vb}=$ Volucella bombylans, $\mathrm{V} p=$ Volucella pellucens. 


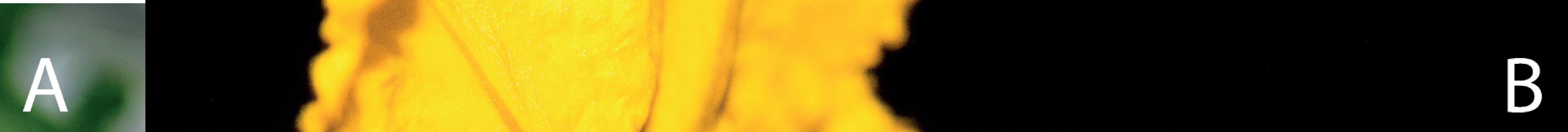

B 


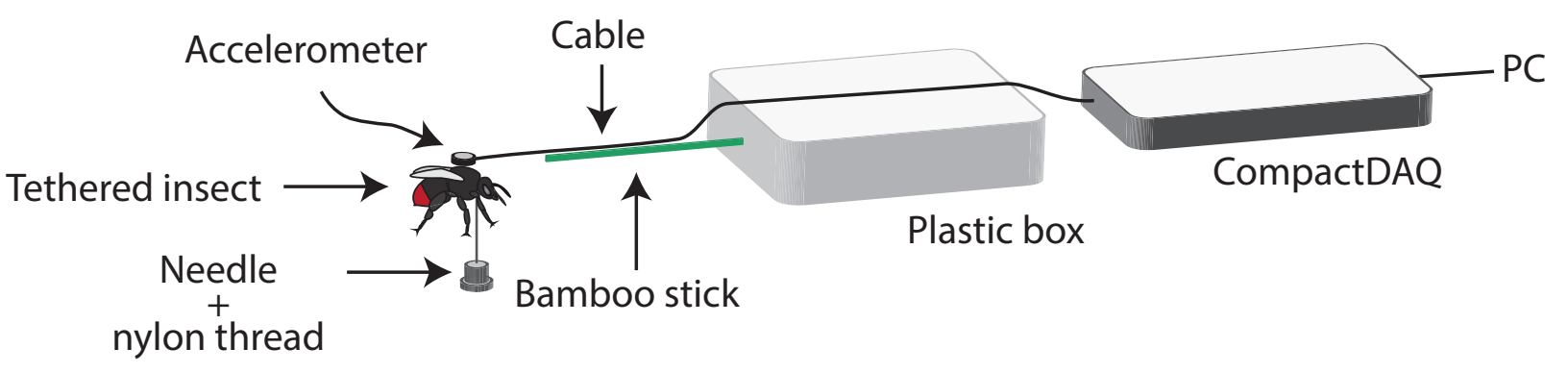



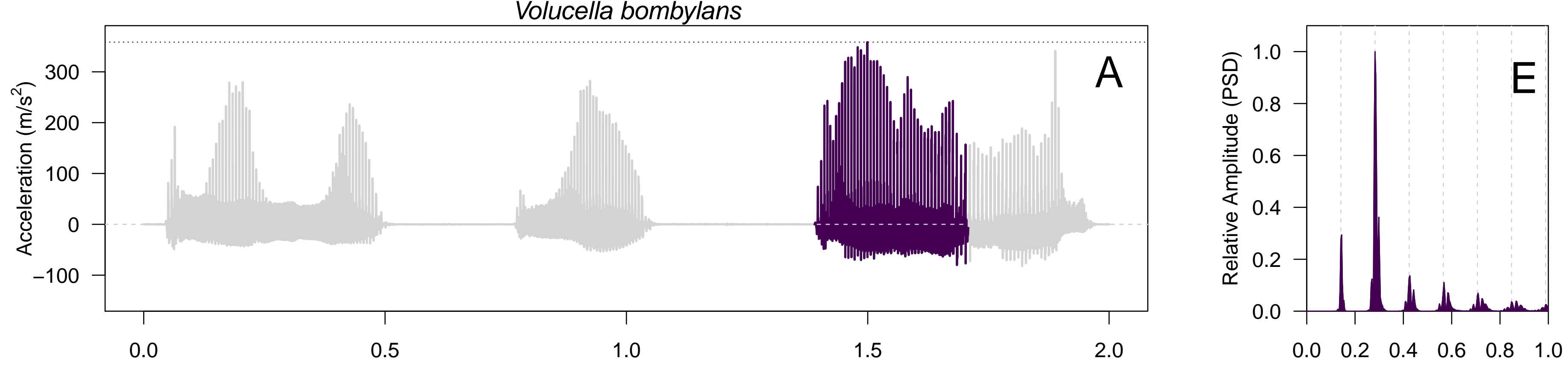

Bombus muscorum
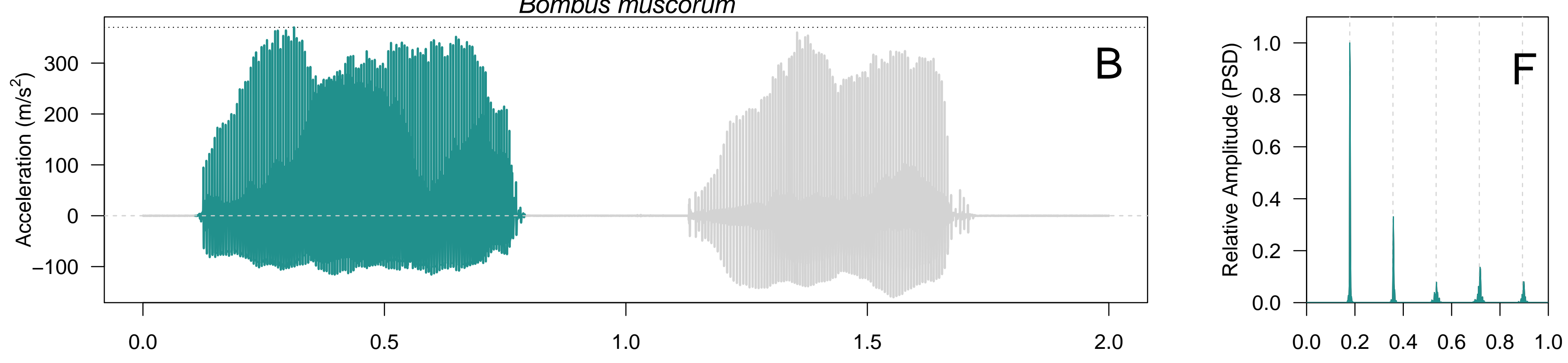

Episyrphus balteatus
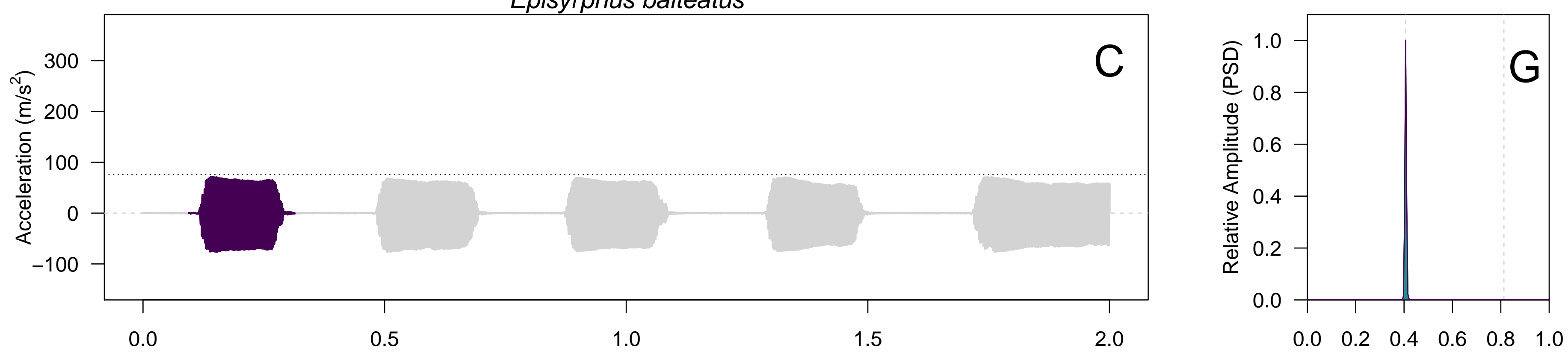

Megachile willughbiella
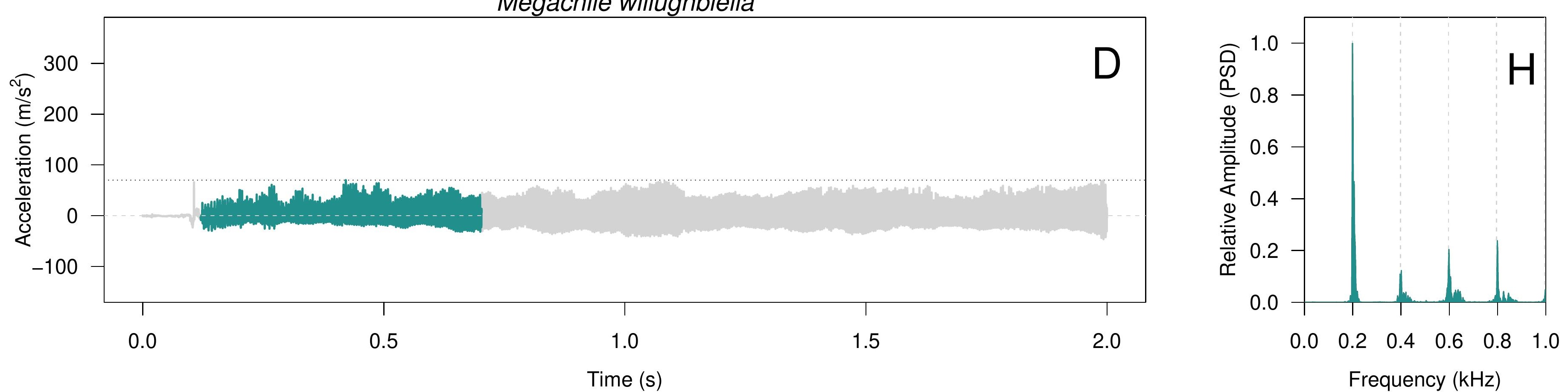


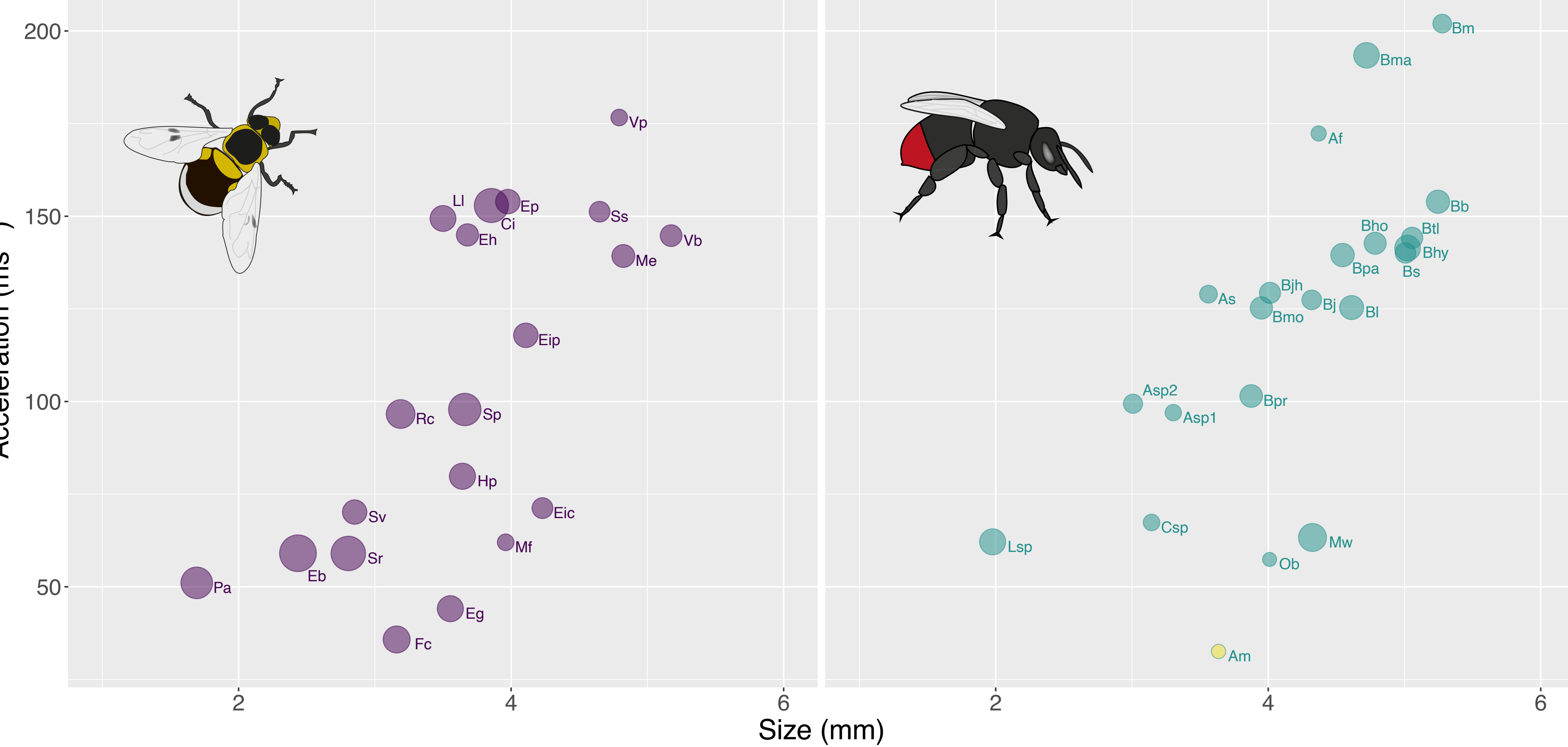


1 Table S1. Number of individuals per species with recorded non-flight thoracic vibrations (defence buzzes). For social bees, female workers and queens are

2 shown separately.

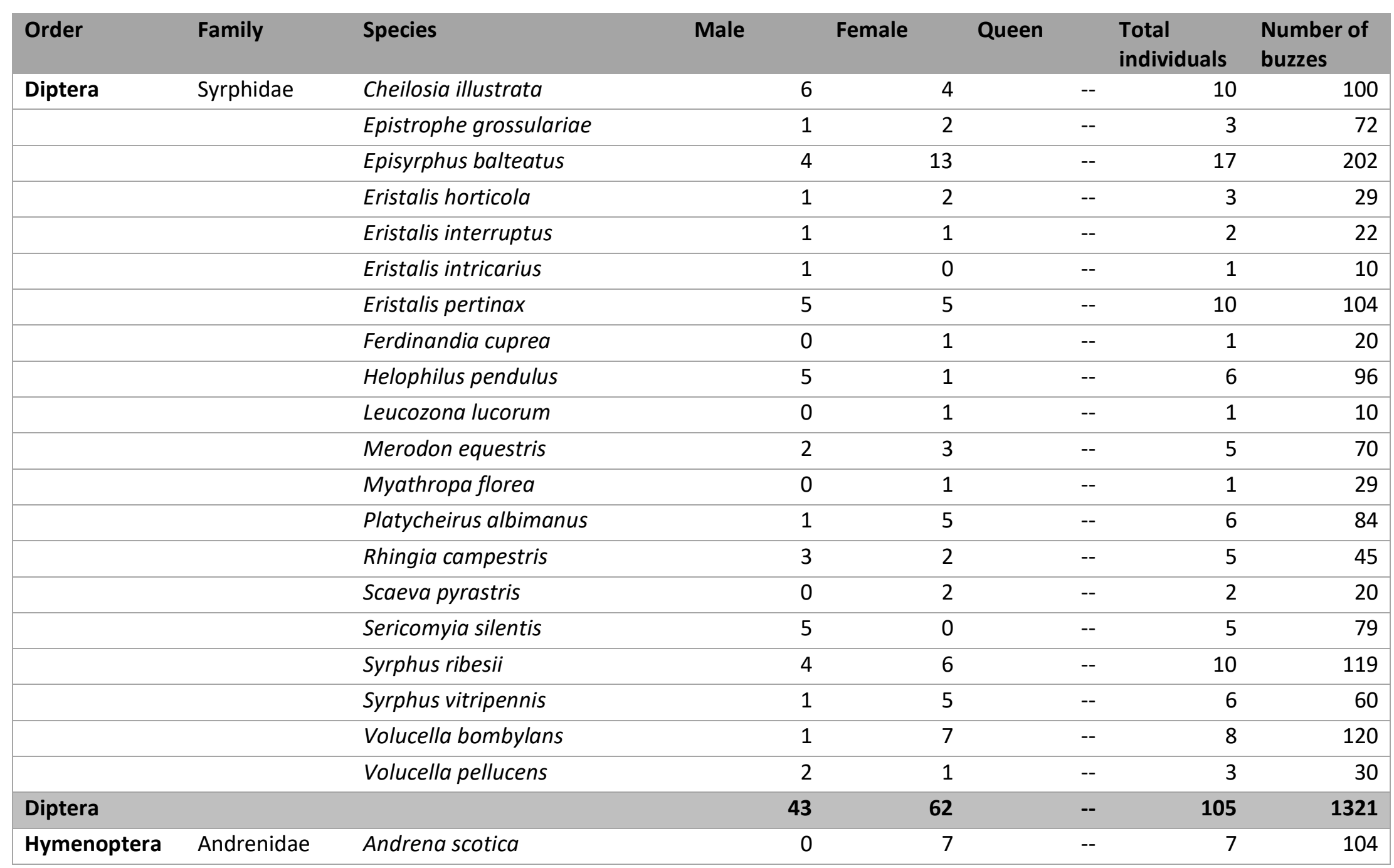




\begin{tabular}{|c|c|c|c|c|c|c|}
\hline & Andrena sp. 1 & 0 & 2 & -- & 2 & 30 \\
\hline & Andrena sp. 2 & 0 & 4 & -- & 4 & 51 \\
\hline Apidae & Anthophora furcata & 0 & 1 & -- & 1 & 10 \\
\hline & Apis mellifera & 0 & 4 & 0 & 4 & 45 \\
\hline & Bombus bohemicus & 7 & 0 & 0 & 7 & 91 \\
\hline & Bombus hortorum & 3 & 14 & 1 & 18 & 241 \\
\hline & Bombus hypnorum & 7 & 8 & 1 & 16 & 200 \\
\hline & Bombus jonellus & 1 & 4 & 2 & 7 & 84 \\
\hline & Bombus jonellus hebridensis & 0 & 13 & 0 & 13 & 174 \\
\hline & Bombus lapidarius & 4 & 13 & 0 & 17 & 206 \\
\hline & Bombus monticola & 0 & 1 & 0 & 1 & 10 \\
\hline & Bombus muscorum & 0 & 10 & 5 & 15 & 166 \\
\hline & Bombus muscorum agricolae & 0 & 9 & 0 & 9 & 173 \\
\hline & Bombus pascuorum & 0 & 11 & 1 & 12 & 138 \\
\hline & Bombus pratorum & 4 & 7 & 0 & 11 & 168 \\
\hline & Bombus sylvestris & 11 & 0 & 0 & 11 & 173 \\
\hline & Bombus terrestris-lucorum & 13 & 15 & 1 & 29 & 374 \\
\hline Colletidae & Colletes sp. & 1 & 1 & -- & 2 & 29 \\
\hline Halictidae & Lasioglossum sp. & 0 & 2 & -- & 2 & 24 \\
\hline Megachilidae & Megachile willughbiella & 0 & 5 & -- & 5 & 66 \\
\hline & Osmia bicornis & 0 & 1 & -- & 1 & 40 \\
\hline Hymenoptera & & 51 & 132 & 11 & 194 & 2597 \\
\hline Total & & 94 & 194 & 11 & 299 & 3918 \\
\hline
\end{tabular}

